\title{
Healthcare Encounters Reason Not Done
}

National Cancer Institute

\section{Source}

National Cancer Institute. Healthcare Encounters Reason Not Done. NCI Thesaurus. Code C123993.

The explanation given as to why the healthcare encounter was not assessed. 